\title{
Video Article \\ "Liver-on-a-Chip" Cultures of Primary Hepatocytes and Kupffer Cells for Hepatitis B Virus Infection
}

\author{
Ana Maria Ortega-Prieto ${ }^{1}$, Jessica Katy Skelton ${ }^{1}$, Catherine Cherry ${ }^{1}$, Marco Antonio Briones-Orta ${ }^{1}$, Charlotte Alexandra Hateley ${ }^{1}$, Marcus Dorner ${ }^{1}$ \\ ${ }^{1}$ Section of Virology, Department of Medicine, Imperial College
}

Correspondence to: Ana Maria Ortega-Prieto at a.ortega-prieto@imperial.ac.uk, Marcus Dorner at m.dorner@imperial.ac.uk

URL: https://www.jove.com/video/58333

DOI: doi: $10.3791 / 58333$

Keywords: Immunology and Infection, Issue 144, Hepatitis B virus, microfluidic device, tissue culture, organ-on-a-chip, bioengineering, hepatocytes, Kupffer cells

Date Published: 2/19/2019

Citation: Ortega-Prieto, A.M., Skelton, J.K., Cherry, C., Briones-Orta, M.A., Hateley, C.A., Dorner, M. "Liver-on-a-Chip" Cultures of Primary Hepatocytes and Kupffer Cells for Hepatitis B Virus Infection. J. Vis. Exp. (144), e58333, doi:10.3791/58333 (2019).

\section{Abstract}

Despite the exceptional infectivity of the hepatitis B virus (HBV) in vivo, where only three viral genomes can result in a chronicity of experimentally infected chimpanzees, most in vitro models require several hundreds to thousands of viral genomes per cell in order to initiate a transient infection. Additionally, static $2 \mathrm{D}$ cultures of primary human hepatocytes $(\mathrm{PHH})$ allow only short-term studies due to their rapid dedifferentiation. Here, we describe 3D liver-on-a-chip cultures of $\mathrm{PHH}$, either in monocultures or in cocultures with other nonparenchymal liverresident cells. These offer a significant improvement to studying long-term HBV infections with physiological host cell responses. In addition to facilitating drug efficacy studies, toxicological analysis, and investigations into pathogenesis, these microfluidic culture systems enable the evaluation of curative therapies for HBV infection aimed at eliminating covalently closed, circular (ccc)DNA. This presented method describes the set-up of $\mathrm{PHH}$ monocultures and $\mathrm{PHH} /$ Kupffer cell co-cultures, their infection with purified $\mathrm{HBV}$, and the analysis of host responses. This method is particularly applicable to the evaluation of long-term effects of HBV infection, treatment combinations, and pathogenesis.

\section{Video Link}

The video component of this article can be found at https://www.jove.com/video/58333/

\section{Introduction}

The study of HBV has been complicated by the poor susceptibility of culture systems, requiring several hundreds to thousands of HBV genome copies per cell to initiate the infection ${ }^{1}$. Furthermore, primary human hepatocytes are generally exceptionally fragile and rapidly dedifferentiate during conventional cultures ${ }^{2}$. This is mainly due to the fact that the flat and hard plastic surfaces do not mimic the natural extracellular environments found within the liver and the general lack of oxygenation of the cultures in the absence of microfluidic circulation. Conventional static hepatocyte cultures on collagen-coated plates rapidly dedifferentiate and lose their susceptibility to HBV infection ${ }^{3}$. Here, we describe the set-up and infection of PHH grown in 3D liver-on-a-chip cultures, which are vastly advantageous over conventional 2D static PHH cultures on collagen-coated plates due to their extended metabolic and functional competence, facilitating long-term cultures of at least 40 days ${ }^{4}$. In this system, $\mathrm{PHH}$ are seeded on collagen-coated scaffolds, which are continually perfused with growth medium to supply oxygen and nutrients to the cells. Even though alternative culture systems for $\mathrm{PHH}$ based on complex cocultures of murine fibroblasts or 3D growth in spheroids have been validated and are susceptible to HBV infection using multiplicities of infection of 500 genome equivalents (GE) of HBV per cell, 3D liver-ona-chip cultures remain the sole in vitro model system susceptible to $0.05 \mathrm{GE}$ of HBV per cell ${ }^{4}$. This is additionally underpinned by the necessity of using high concentrations of dimethyl sulfoxide (DMSO) and polyethylene glycol (PEG) to establish HBV infection in these cultures, which is dispensable for the infection of 3D liver-on-a-chip culture systems ${ }^{4}$. Among the major hallmarks of HBV infection is the cccDNA pool, which acts as the transcriptional template for all de novo-produced virions ${ }^{5,6}$. Even though cccDNA can be detected in conventional hepatocyte cultures ${ }^{7,8}$, it remains unclear as to whether the regulation of cccDNA and any therapeutic approaches aimed at its elimination are recapitulated in partially or completely dedifferentiated hepatocytes. We have shown that cccDNA is functionally formed in 3D liver-on-a-chip cultures, responds to physiological stimuli, and can be targeted by interfering with the accessibility of the transcriptional machinery to the cccDNA genome ${ }^{4}$.

Host responses to HBV infection in 3D liver-on-a-chip mimic those observed in HBV-infected patients, enabling the identification of biomarkers for infection, as well as therapeutic success. Among the unique features of liver-on-a-chip cultures is the ability to evaluate long-term host responses between $\mathrm{PHH}$ and other nonparenchymal cells within the liver, including Kupffer cells ${ }^{4}$, stellate cells ${ }^{9}$, and liver sinusoidal endothelial cells ${ }^{10,11}$. This offers the unique opportunity to evaluate cell/cell interactions in a complex 3D microenvironment.

Additionally, the extended culture period of this platform facilitates the evaluation of sequential drug treatments and their impact on HBV persistence, which are not possible using conventional hepatocyte culture systems.

This protocol describes how 3D liver-on-a-chip cultures are generated, either for monocultures of $\mathrm{PHH}$ or for cocultures of $\mathrm{PHH}$ with Kupffer cells. Furthermore, we describe the production of purified HBV for low-multiplicity-of-infection studies, as well as the subsequent analysis of host and viral responses. 


\section{Assembly and Equilibration of Plates}

1. Ensure that both the compressor and the vacuum pump associated with the LiverChip platform are turned on. Perform the assembly and equilibration of the plates in a class II cabinet.

2. Aseptically assemble the microfluidic plates by placing a sterile membrane between the plate base and adding the well-containing top plate (Figure 1a).

3. Ensure that the sterile membrane smoothly rests on the two pins of the base plate, since uneven membrane placement compromises the microfluidic circulation.

4. Add a sterile plate lid and tighten the screws at the base of the plate using an automated precision torque to $33 \mathrm{lb}$ using a spiral tightening sequence. Ensure that all screws are tightened to $35 \mathrm{lb}$ using a manual torque. During this step, ensure the screws are tightened symmetrically (Figure 1a).

5. Prewarm hepatocyte seeding medium containing Williams $E$ medium, primary hepatocyte thawing, and plating supplements, $5 \%$ fetal bovine serum (FBS), and $1 \mu \mathrm{M}$ dexamethasone to $37^{\circ} \mathrm{C}$ before priming.

6. Prime the completely assembled plate by placing it within the washing dock and adding $400 \mu \mathrm{L}$ of hepatocyte seeding medium to the reservoir side of each well. Ensure the plate snaps into the washing dock completely.

7. Initiate flow in the upward direction for $3.5 \mathrm{~min}$ at $1 \mu \mathrm{L} / \mathrm{s}$. The successful function of the microfluidic circulation can be ascertained through the red indicators at the side of the plate (Figure 1a).

8. Once the medium is pumped to the cell growth side of the plate, ensuring the correct assembly of the flow channel, add an additional $1.2 \mathrm{~mL}$ of hepatocyte seeding medium.

9. Carefully transfer the plate into the docking station within a humidified incubator at $37{ }^{\circ} \mathrm{C}$ and $5 \% \mathrm{CO}_{2}$ and initiate flow in the upward direction at a flow rate of $1 \mu \mathrm{L} / \mathrm{s}$ for $16 \mathrm{~h}$ (Figure 1c).

10. Transfer the plate to the washing dock and eliminate bubbles in the well by gently pipetting up and down.

11. Add one sterile, round filter paper, followed by a cell attachment scaffold and a retaining ring, to each well using sterile forceps. Press down each well with a sterile plunger to lock the retaining rings and scaffolds into place (Figure 1b).

12. Aspirate all medium and add $400 \mu \mathrm{L}$ of prewarmed hepatocyte seeding medium gently over the scaffold and initiate flow in the downward direction for $3.5 \mathrm{~min}$ at $1 \mu \mathrm{L} / \mathrm{s}$.

13. Aspirate all medium pumped out of the reservoir side of the plate. This step is necessary to replace the medium contained in the flow channel.

14. Add $1.4 \mathrm{~mL}$ of hepatocyte seeding medium to each well before returning the plate to the dock to complete the total volume per well. The volume per well is now $1.6 \mathrm{~mL}(1.4 \mathrm{~mL}$ in the well and $0.2 \mathrm{~mL}$ in the flow channel).

\section{Thawing and Seeding of Hepatocytes for Monocultures}

1. Prewarm hepatocyte thawing medium and hepatocyte seeding medium to $37^{\circ} \mathrm{C}$ prior to thawing one vial of $\mathrm{PHH}$ according to the suppliers' instructions. Use a centrifuge at room temperature during this step to avoid abrupt temperature changes. Perform the thawing and seeding of the hepatocytes in a class II cabinet.

2. Resuspend the cells in $1 \mathrm{~mL}$ of hepatocyte seeding medium and count the cells using trypan blue. Ensure that the viability of the cells is above $90 \%$

3. Keep the cells on ice until they are added to the wells.

4. Transfer the equilibrated and fully assembled plate to the washing dock and aspirate all medium from the wells.

5. Add 600,000 hepatocytes to each well in a $500 \mu \mathrm{L}$ volume of hepatocyte seeding medium.

6. Initiate flow in the downward direction at a flow rate of $1 \mu \mathrm{L} / \mathrm{s}$ and bring the total volume in the well to $1.6 \mathrm{~mL}$ by adding $900 \mu \mathrm{L}$ of hepatocyte seeding medium.

7. Transfer the plate to the docking station within a humidified incubator at $37^{\circ} \mathrm{C}$ and with $5 \% \mathrm{CO}_{2}$.

8. Initiate flow in the downward direction at a flow rate of $1 \mu \mathrm{L} / \mathrm{s}$ for $8 \mathrm{~h}$, followed by a flow reversal to the upward direction at a flow rate of $1 \mu \mathrm{L} /$ $\mathrm{s}$ for $8 \mathrm{~h}$.

9. Transfer the plate to the washing dock and aspirate all medium from the wells.

10. Add $400 \mu \mathrm{L}$ of hepatocyte maintenance medium (Williams $\mathrm{E}$ medium supplemented with hepatocyte maintenance supplements and $100 \mathrm{nM}$ dexamethasone) to each well and initiate flow in the downward direction at a flow rate of $1 \mu \mathrm{L} / \mathrm{s}$ for $3.5 \mathrm{~min}$.

11. Aspirate all medium from the reservoir and add $1.4 \mathrm{~mL}$ of hepatocyte maintenance medium (Figure 1d).

12. Replace the medium with hepatocyte maintenance medium every $48 \mathrm{~h}$. To ensure all medium in the well is replaced, perform a washing step before the addition of fresh hepatocyte maintenance medium.

13. For the washing step, transfer the plate to the washing dock, aspirate all medium from the wells, and add $400 \mu \mathrm{L}$ of maintenance medium.

14. Initiate flow in the downward direction at $1 \mu \mathrm{L} / \mathrm{s}$ for $3.5 \mathrm{~min}$. Aspirate all medium appearing on the reservoir side of the wells.

15. Add $1.4 \mathrm{~mL}$ of hepatocyte maintenance medium and, within a humidified incubator at $37{ }^{\circ} \mathrm{C}$ and with $5 \% \mathrm{CO}_{2}$, transfer the plate into the docking station and initiate flow in the upward direction at a flow rate of $1 \mu \mathrm{L} / \mathrm{s}$ for $48 \mathrm{~h}$ (Figure $1 \mathrm{f}$ ).

NOTE: For hepatocyte monocultures used as controls for cocultures, in order to ensure controlled conditions, a second type of maintenance medium is used, which is specific for use in the cocultures with primary human Kupffer cells. $48 \mathrm{~h}$ after replacing the hepatocyte seeding medium with hepatocyte maintenance medium (day 3 post-seeding), the regular hepatocyte maintenance medium will be replaced with coculture maintenance medium II, especially in monocultures of $\mathrm{PHH}$ when comparing to cocultures of both $\mathrm{PHH}$ and Kupffer cells, as the medium components differ slightly. 


\section{Thawing and Seeding of Kupffer Cells and Hepatocytes for Co-cultures}

1. In order to ensure an accurate comparison of results, always compare $\mathrm{PHH} / \mathrm{Kupffer}$ cell cocultures to $\mathrm{PHH}$ monocultures

2. For cocultures of PHH and Kupffer cells, thaw one vial of Kupffer cells in advanced Dulbecco's modified Eagle's medium (AdDMEM) without dexamethasone but supplemented with primary hepatocyte thawing and plating supplements (coculture seeding medium) according to the suppliers' instructions. Perform the thawing and seeding of the Kupffer cells and hepatocytes in a class II cabinet.

3. Resuspend the cells in $1 \mathrm{~mL}$ of coculture seeding medium and count the cells using trypan blue. Ensure that the viability of the cells is above $90 \%$.

4. Keep the cells on ice prior to adding them to the wells to avoid cell adhesion.

5. Follow the instructions in steps 2.1-2.3 for the thawing of primary human hepatocytes.

6. Transfer the equilibrated and fully assembled plate to the washing dock and aspirate all medium from the wells.

7. Add $60,000 \mathrm{Kupffer}$ cells and/or 600,000 hepatocytes to each well in a total volume of $250 \mu \mathrm{L}$ each of coculture seeding medium.

8. Initiate flow in the downward direction at a flow rate of $1 \mu \mathrm{L} / \mathrm{s}$ and add $900 \mu \mathrm{L}$ of coculture seeding medium to each well.

9. Transfer the plate into the docking station within a humidified incubator at $37^{\circ} \mathrm{C}$ and with $5 \% \mathrm{CO}_{2}$.

10. Initiate flow in the downward direction at a flow rate of $1 \mu \mathrm{L} / \mathrm{s}$ for $8 \mathrm{~h}$, followed by flow reversal to the upward direction at a flow rate of $1 \mu \mathrm{L} / \mathrm{s}$ for $8 \mathrm{~h}$.

11. Transfer the plate to the washing dock and aspirate all medium from the wells.

12. Add $400 \mu \mathrm{L}$ of coculture maintenance medium I (AdDMEM without dexamethasone but supplemented with hepatocyte maintenance supplements) to each well and initiate flow in the downward direction at a flow rate of $1 \mu \mathrm{L} / \mathrm{s}$ for $3.5 \mathrm{~min}$.

13. Aspirate all medium from the reservoir side and add $1.4 \mathrm{~mL}$ of coculture maintenance medium I to each well.

14. Transfer the plate into the docking station within a humidified incubator at $37{ }^{\circ} \mathrm{C}$ and with $5 \% \mathrm{CO}_{2}$ and initiate flow in the upward direction at a flow rate of $1 \mu \mathrm{L} / \mathrm{s}$ for $48 \mathrm{~h}$.

15. Transfer the plate to the washing dock and aspirate all medium from the wells. Add $400 \mu \mathrm{L}$ of coculture maintenance medium II (Williams $\mathrm{E}$ medium without dexamethasone but supplemented with $100 \mathrm{nM}$ hydrocortisone and hepatocyte maintenance supplements) and initiate flow in the downward direction at $1 \mu \mathrm{L} / \mathrm{s}$ for $3.5 \mathrm{~min}$.

16. Aspirate all medium appearing on the reservoir side of the wells.

17. Add $1.4 \mathrm{~mL}$ of coculture maintenance medium II and transfer the plate into the docking station within a humidified incubator at $37{ }^{\circ} \mathrm{C}$ and with $5 \% \mathrm{CO}_{2}$.

18. Initiate flow in the upward direction at a flow rate of $1 \mu \mathrm{L} / \mathrm{s}$ for $48 \mathrm{~h}$ (Figure 1e).

19. Replace the medium every $48 \mathrm{~h}$ with coculture maintenance medium II. To ensure all medium in the well is replaced, perform a washing step before the addition of fresh medium.

20. To wash, transfer the plate to the washing dock, aspirate all medium from the wells, and add $400 \mu \mathrm{L}$ of coculture maintenance medium II.

21. Initiate flow in the downward direction at $1 \mu \mathrm{L} / \mathrm{s}$ for $3.5 \mathrm{~min}$. Aspirate all medium appearing on the reservoir side of the wells.

22. Add $1.4 \mathrm{~mL}$ of coculture maintenance medium II and transfer the plate into the docking station within a humidified incubator at $37{ }^{\circ} \mathrm{C}$ and with $5 \% \mathrm{CO}_{2}$, and initiate flow in the upward direction at a flow rate of $1 \mu \mathrm{L} / \mathrm{s}$ for $48 \mathrm{~h}$ (Figure 1f).

\section{Production of an Infectious Hepatitis B Virus for Infection Studies}

1. Perform this section of the protocol in a containment level III lab. Do the seeding, medium changes, medium collection, and virus concentration in a class II cabinet.

2. Culture HBV-producing cells (e.g., HepDE19, HepAD38) in collagen-coated T1000 5-layer flasks in $120 \mathrm{~mL}$ of complete DMEM/F12 (10\% FBS, penicillin/steptomycin, nonessential amino acids, $500 \mu \mathrm{g} / \mathrm{mL} \mathrm{G} 418$, and $1 \mu \mathrm{g} / \mathrm{mL}$ tetracycline) until they reach $90 \%$ confluency.

3. Change the medium to induction medium (complete DMEM without tetracycline) to induce the HBV production.

4. Collect the complete medium volume every $48 \mathrm{~h}$ for 12 days post-withdrawal of tetracycline and store it at $4{ }^{\circ} \mathrm{C}$.

5. Filter the collected medium through a $0.45 \mu \mathrm{m}$ bottle top filter.

6. Add sterile PEG 8000 in phosphate-buffered saline (PBS) to the collected medium to a final concentration of $4 \% \mathrm{w} / \mathrm{w}$, mix by inverting $8 \mathrm{x}-$ $10 \mathrm{x}$, and incubate at $4{ }^{\circ} \mathrm{C}$ for $16 \mathrm{~h}$. Centrifuge at $10,000 \times g$ for $1 \mathrm{~h}$ at $4{ }^{\circ} \mathrm{C}$ to collect the PEG-precipitated virus and resuspend the pellet in PBS containing $10 \%$ FBS.

7. Combine the PEG-precipitated virus from all harvesting time points and layer it on top of a $20 \%$ sucrose cushion. Centrifuge at $140,000 \times g$ for $16 \mathrm{~h}$ at $4{ }^{\circ} \mathrm{C}$ using an SW28 rotor.

8. Aspirate the supernatant and resuspend the pellet in PBS supplemented with $10 \% \mathrm{FBS}$, and aliquot and store it at $-80{ }^{\circ} \mathrm{C}$.

9. Determine the HBV DNA copy number present in the supernatant by HBV DNA qPCR (step 6).

\section{Infection of 3D Cultures with HBV}

1. Perform infections in a class II cabinet within a containment level III lab.

2. 3 days after seeding the monocultures or cocultures, thaw the required number of HBV-containing aliquots at room temperature and dilute the required virus dose in $1.8 \mathrm{~mL}$ of hepatocyte maintenance medium or coculture maintenance medium II per well, respectively.

3. This 1.8- $\mathrm{mL}$ diluted virus is sufficient for the washing step $(400 \mu \mathrm{L})$ and the replacement of medium in the well $(1.4 \mathrm{~mL})$. However, the required multiplicity of infection needs to be adjusted to account for the final culture volume of $1.6 \mathrm{~mL}$.

4. Transfer the plate to the washing dock and aspirate all medium from the wells. Add $400 \mu \mathrm{L}$ of HBV-containing medium and initiate flow in the downward direction at $1 \mu \mathrm{L} / \mathrm{s}$ for $3.5 \mathrm{~min}$. Aspirate all medium appearing on the reservoir side of the wells.

5. Add $1.4 \mathrm{~mL}$ of HBV-containing maintenance medium/coculture maintenance medium II per well and transfer the plate into the docking station within a humidified incubator at $37^{\circ} \mathrm{C}$ and with $5 \% \mathrm{CO}_{2}$. Initiate flow in the downward direction at a flow rate of $1 \mu \mathrm{L} / \mathrm{s}$ for $8 \mathrm{~h}$, followed by a reversal to the upward direction at a flow rate of $1 \mu \mathrm{L} / \mathrm{s}$.

6. $24 \mathrm{~h}$ following the addition of HBV, transfer the plate to the washing dock and aspirate all medium from the wells. 
7. Wash each well in the plate $3 x$ with the corresponding medium, according to the type of culture as outlined in steps $2.12-2.14$, to eliminate leftover virus from the well. In contrast to steps $2.12-2.14$, add $1.6 \mathrm{~mL}$ of medium in every well to account for the extra volume to be sampled to exclude inoculum carryover (Figure 19).

8. Following these washing steps, collect $200 \mu \mathrm{L}$ of medium from each well to confirm the complete removal of the HBV inoculum by quantification of extracellular HBV DNA.

9. Transfer the plate to the docking station within a humidified incubator at $37^{\circ} \mathrm{C}$ and with $5 \% \mathrm{CO}_{2}$, and initiate flow in the upward direction at a flow rate of $1 \mu \mathrm{L} / \mathrm{s}$ for $48 \mathrm{~h}$.

10. $48 \mathrm{~h}$ later, collect the complete well volume for downstream analysis, followed by three washes with hepatocyte maintenance medium as outlined in steps 2.12-2.14. Replace the medium and wash each well $3 \mathrm{x}$ every $48 \mathrm{~h}$ until experimental termination.

\section{Quantification of Extracellular HBV DNA}

1. Isolate total DNA from the culture supernatants according to the manufacturer's instructions with the addition of $1 \mu \mathrm{g}$ of carrier RNA in a containment level III lab to ensure the virus inactivation in the samples prior to moving them to a different area.

2. Prepare a master mix containing quantitative PCR master mix, $600 \mathrm{nM}$ forward primer, $600 \mathrm{nM}$ reverse primer, and $300 \mathrm{nM}$ of probe.

3. Add $7 \mu \mathrm{L}$ of the master mix into each well of a 384-well plate.

4. Add $5 \mu \mathrm{L}$ of DNA samples in duplicate, a no-template control, and duplicates of serially diluted HBV genome-containing plasmid-based standard (e.g., pCMV-HBV) ranging from $10^{9}$ copies per reaction to $10^{2}$ copies per reaction to each well of the qPCR plate.

5. Place an adhesive cover over the plate and ensure that each well is sealed correctly.

6. Centrifuge the plate for $1 \mathrm{~min}$ at $300 \times \mathrm{g}$

7. Start the $\mathrm{gPCR}$ run according to the manufacturer's instructions. The cycle conditions for real-time PCR are $95^{\circ} \mathrm{C}$ for 10 min, followed by 40 cycles of $95^{\circ} \mathrm{C}$ for $15 \mathrm{~s}$ and $60^{\circ} \mathrm{C}$ for $1 \mathrm{~min}$.

8. Quantify the number of HBV DNA copies within the unknown samples according to the standard curve.

\section{Quantification of Intracellular HBV Pregenomic (pg)RNA}

1. Isolate total RNA from the scaffolds according to the manufacturer's instructions. In order to ensure complete cell lysis, vortex each scaffold $3 \mathrm{x}$ for $30 \mathrm{~s}$ followed by centrifugation at $300 \mathrm{xg}$ for $1 \mathrm{~min}$ between each vortexing. Perform the cell lysis in the containment level III lab to ensure the virus inactivation in the samples prior to moving them to a different area.

2. Transcribe cDNA from the isolated RNA according to the manufacturer's instructions.

3. The cycle conditions for the retrotranscription are $25^{\circ} \mathrm{C}$ for $10 \mathrm{~min}, 37^{\circ} \mathrm{C}$ for $120 \mathrm{~min}$, and $85^{\circ} \mathrm{C}$ for $5 \mathrm{~min}$.

4. Keep the cDNA samples at $4{ }^{\circ} \mathrm{C}$ for short-term or at $-20^{\circ} \mathrm{C}$ for long-term storage.

5. Prepare master mixes for pgRNA and RPS11 containing quantitative PCR master mix and forward and reverse primers for pgRNA and RPS11 (used as housekeeping gene) at a final concentration of $0.2 \mu \mathrm{M}$.

6. Add $7.5 \mu \mathrm{L}$ of the master mix and $2.5 \mu \mathrm{L}$ of cDNA per well on a 384-well plate. Measure RPS11 and pgRNA of each sample in duplicate and include a no-template control well for both genes.

7. Place an adhesive cover over the plate and ensure that each well is sealed completely.

8. Centrifuge the plate for $1 \mathrm{~min}$ at $300 \times g$.

9. Insert the plate into the qPCR cycler and start the qPCR run using the standard quantitative PCR protocol according to the manufacturer's instructions. The cycle conditions for real-time PCR are $50{ }^{\circ} \mathrm{C}$ for $2 \mathrm{~min}, 95^{\circ} \mathrm{C}$ for $2 \mathrm{~min}$, followed by 40 cycles of $95{ }^{\circ} \mathrm{C}$ for $15 \mathrm{~s}$ and $60{ }^{\circ} \mathrm{C}$ for $1 \mathrm{~min}$.

10. Calculate the expression of pgRNA relative to RPS11.

\section{Immunofluorescence Staining of Viral Antigen}

1. Remove the retaining ring from the well and remove the scaffold with forceps in a class II cabinet in the containment level III lab.

2. Fix the cell-containing scaffolds with $4 \%$ paraformaldehyde in $1 \mathrm{~mL}$ of PBS for $30 \mathrm{~min}$ at room temperature in the containment level III lab. The following steps can be performed in a different area.

3. Wash the scaffolds $3 x$ with $1 \mathrm{~mL}$ of PBS.

4. Permeabilize the cells using $0.1 \%$ Triton-X 100 in $1 \mathrm{~mL}$ of PBS for $1 \mathrm{~h}$ at room temperature.

5. Wash the scaffolds $3 \mathrm{x}$ with $1 \mathrm{~mL}$ of PBS.

6. Block non-specific binding by incubation of the scaffolds with $1 \% \mathrm{BSA}$ in $1 \mathrm{~mL}$ of PBS for $16 \mathrm{~h}$ at $4{ }^{\circ} \mathrm{C}$.

7. Wash the scaffolds $3 x$ with $1 \mathrm{~mL}$ of PBS.

8. Perform primary antibody staining using rabbit anti-hepatitis $\mathrm{B}$ virus core antigen at a dilution of $1: 200$ in $1 \% \mathrm{BSA}$ in $1 \mathrm{~mL}$ of PBS for $16 \mathrm{~h}$ at $4{ }^{\circ} \mathrm{C}$.

9. Wash the scaffolds $1 \mathrm{x}$ with $0.1 \%$ Tween in $1 \mathrm{~mL}$ of PBS (PBS-Tween) and $3 \mathrm{x}$ with $1 \mathrm{~mL}$ of PBS

10. Perform secondary antibody staining using goat anti-rabbit $\lg \mathrm{G}(\mathrm{H}+\mathrm{L})$ cross-adsorbed Alexa Fluor 594-conjugated secondary antibody at a dilution of $1: 2,000$ in $1 \%$ BSA in $1 \mathrm{~mL}$ of PBS for $16 \mathrm{~h}$ at $4{ }^{\circ} \mathrm{C}$

11. Wash the scaffolds $1 \mathrm{x}$ with $1 \mathrm{~mL}$ of $0.1 \%$ PBS-Tween and $3 \mathrm{x}$ with $1 \mathrm{~mL}$ of PBS.

12. Counterstain the scaffolds using DAPI in $1 \mathrm{~mL}$ of PBS at a concentration of $2 \mu \mathrm{g} / \mathrm{mL}$ for $10 \mathrm{~min}$ at room temperature.

13. Wash the scaffolds $1 \mathrm{x}$ with $1 \mathrm{~mL}$ of $0.1 \%$ PBS-Tween and $3 \mathrm{x}$ with $1 \mathrm{~mL}$ of PBS.

14. Transfer the scaffolds to a microscope slide and mount it for imaging.

15. Image the scaffolds using a fluorescence microscope.

\section{Human Albumin ELISA}

1. Perform this section of the protocol in a class II cabinet allocated in the containment level III lab if working with infectious material. 
2. To evaluate the viability and metabolic functionality of $\mathrm{PHH}$, evaluate human albumin production by ELISA.

3. Coat 96 -well plates with $50 \mu \mathrm{L}$ per well of goat anti-human antibody diluted 1:800 in coating buffer (100 mM bicarbonate/carbonate, pH 9.6$)$. Cover the plates and incubate for $2 \mathrm{~h}$ at $37^{\circ} \mathrm{C}$ or overnight at $4{ }^{\circ} \mathrm{C}$.

4. Aspirate the coating antibody from the plate and wash it $4 \mathrm{x}$ with $200 \mu \mathrm{L}$ of $0.05 \%$ PBS-Tween.

5. Add $200 \mu \mathrm{L}$ of blocking buffer (1\% BSA in PBS), cover the plates, and incubate them for $1 \mathrm{~h}$ at $37^{\circ} \mathrm{C}$ or store them at $4{ }^{\circ} \mathrm{C}$ for $3 \mathrm{months}$. For long-term storage, add $0.05 \%$ sodium azide to the blocking buffer.

6. Aspirate the blocking buffer and wash $1 \mathrm{x}$ with $200 \mu \mathrm{L}$ of $0.05 \%$ PBS-Tween.

7. Add $50 \mu \mathrm{L}$ of previously diluted samples per well (1:100). The sample diluent contains $1 \% \mathrm{BSA}$ in $0.05 \%$ PBS-Tween. Incubate for $1 \mathrm{~h}$ at $37^{\circ} \mathrm{C}$ or overnight at $4{ }^{\circ} \mathrm{C}$.

NOTE: Incubate the standards at the same time as the samples. A concentration range of $500-0.488 \mathrm{ng} / \mathrm{mL}(1: 2$ serial dilutions) is recommended. Perform all serial dilutions of human albumin in sample diluent.

8. Aspirate the samples from the plate and wash it $4 x$ with $200 \mu \mathrm{L}$ of $0.05 \%$ PBS-Tween.

9. Add $50 \mu \mathrm{L}$ of HRP-conjugated goat anti-human albumin antibody previously diluted $1: 10,000$ in sample diluent. Incubate for $2 \mathrm{~h}$ at $37{ }^{\circ} \mathrm{C}$ or overnight at $4{ }^{\circ} \mathrm{C}$.

10. Aspirate the antibody from the plate and wash it $6 \mathrm{x}$ with $200 \mu \mathrm{L}$ of $0.05 \%$ PBS-Tween.

11. Add $100 \mu \mathrm{L}$ of TMB reagent and, as soon as the highest standards are fully developed, add $100 \mu \mathrm{L} 1 \mathrm{M} \mathrm{H}_{2} \mathrm{SO}_{4}$ to stop the colorimetric reaction.

12. Read the absorbance at $450 \mathrm{~nm}$ on a 96 -well plate reader for analysis.

\section{Interleukin (IL)6 and Tumor Necrosis Factors (TNF)a Production in 3D Co-cultures}

1. Perform this section of the protocol in a class II cabinet allocated in the containment level III lab if working with infectious material.

2. Quantify the IL6 and TNFa production to evaluate the functionality and viability of the primary Kupffer cells. To induce the production of these cytokines by Kupffer cells, treat cocultures with $1 \mu \mathrm{g} / \mathrm{mL}$ lipopolysaccharide (LPS) $9 \mathrm{~d}$ post-seeding in the coculture maintenance medium II for $48 \mathrm{~h}$.

3. At day 11 post-seeding, harvest the medium from each well and store it at $-80^{\circ} \mathrm{C}$.

4. Measure the IL6 and TNFa concentration in the culture medium by an appropriate assay and according to the manufacturer's instructions.

\section{Representative Results}

We describe a simple and versatile platform for the long-term culture of primary human Kupffer cells and/or hepatocytes and their infection with HBV. Primary human cells are seeded on collagen-coated polystyrene scaffolds within a microfluidic plate assembly, which continuously perfuses the cells with growth medium (Figure 1a).

$\mathrm{PHH}$, which usually are only stable for a limited amount of time in conventional culture systems, can be functionally maintained for extended periods of time. Human albumin, which is secreted by functional hepatocytes and is considered the best marker for the evaluation of hepatic metabolism, is stably and highly expressed by 3D cultures until day 40 post-seeding (Figure 2). For cocultures, Kupffer cell functionality and viability can be evaluated by the secretion of specific cytokines (e.g., IL6 and TNFa). To measure cytokine production, the use of capture-based detection means upon LPS-stimulation of cocultures is recommended (Figure 3).

Cells form hepatic microtissues, usually within 3 days of seeding of $\mathrm{PHH}$, demonstrating functional bile canaliculi and complete cell polarization (Figure 2). In addition to retaining their physiological cellular metabolism, these cultures become exceptionally susceptible to HBV infection. HBV DNA and other viral markers, in contrast to other culture systems, become readily detectable from day 2 post-infection (Figure 4). In addition to secreted markers of viral infection, hepatocyte-containing scaffolds can be retrieved from the cultures and used for the immunofluorescence detection of viral antigens (e.g., HBsAg, $\mathrm{HBcAg}$ ) (Figure 4). Where conventional hepatocyte cultures require inoculation with at least 500 HBV GE per cell and the addition of $2 \%$ DMSO and 4\% PEG, as few as 0.05 HBV GE are able to initiate infection in 3-D cultures without the requirement of DMSO or PEG (Figure 4). 
a

Sterile plate lid

Sterile well-

containing

top plate

Sterile

membrane

Base

plate b

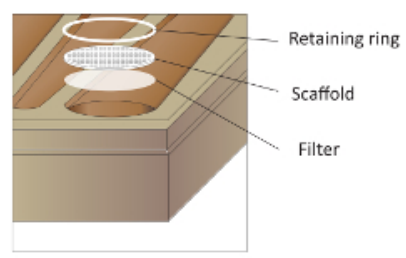

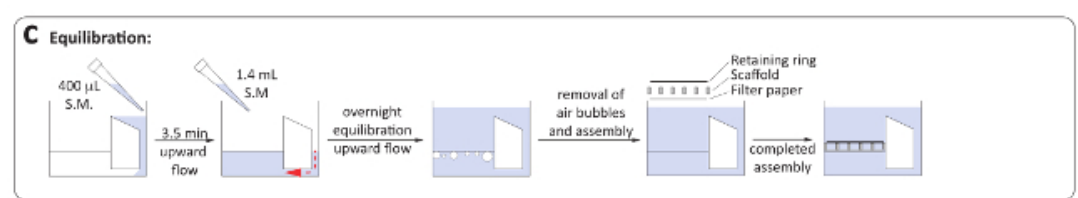

d Seeding (PHH monoculture):
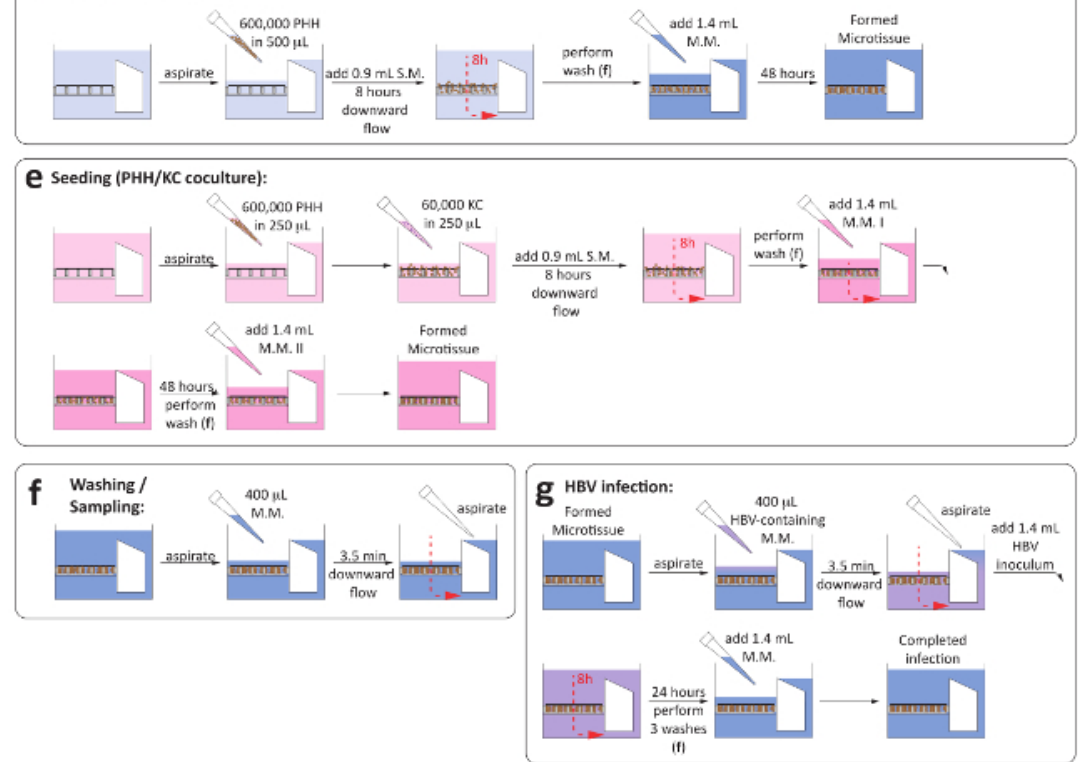

Figure 1: Set-up of 3-D liver-on-a-chip cultures. (a) This is a schematic layout for the assembly of the culture plate in order to ensure the establishment of microfluidic circulation. (b) This panel shows a close-up view of the culture wells, including the filter paper, scaffold, and retaining ring. (c) This panel shows the process of plate equilibration prior to seeding the cultures. The next two panels show the process of seeding for (d) hepatocyte monocultures and (e) hepatocyte/Kupffer cell cocultures. (f) This panel shows the washing steps involved in medium changes. (g) This panel shows the HBV infection set-up, including the removal of inoculum. S.M. = seeding medium, M.M. = maintenance medium. Please click here to view a larger version of this figure. 

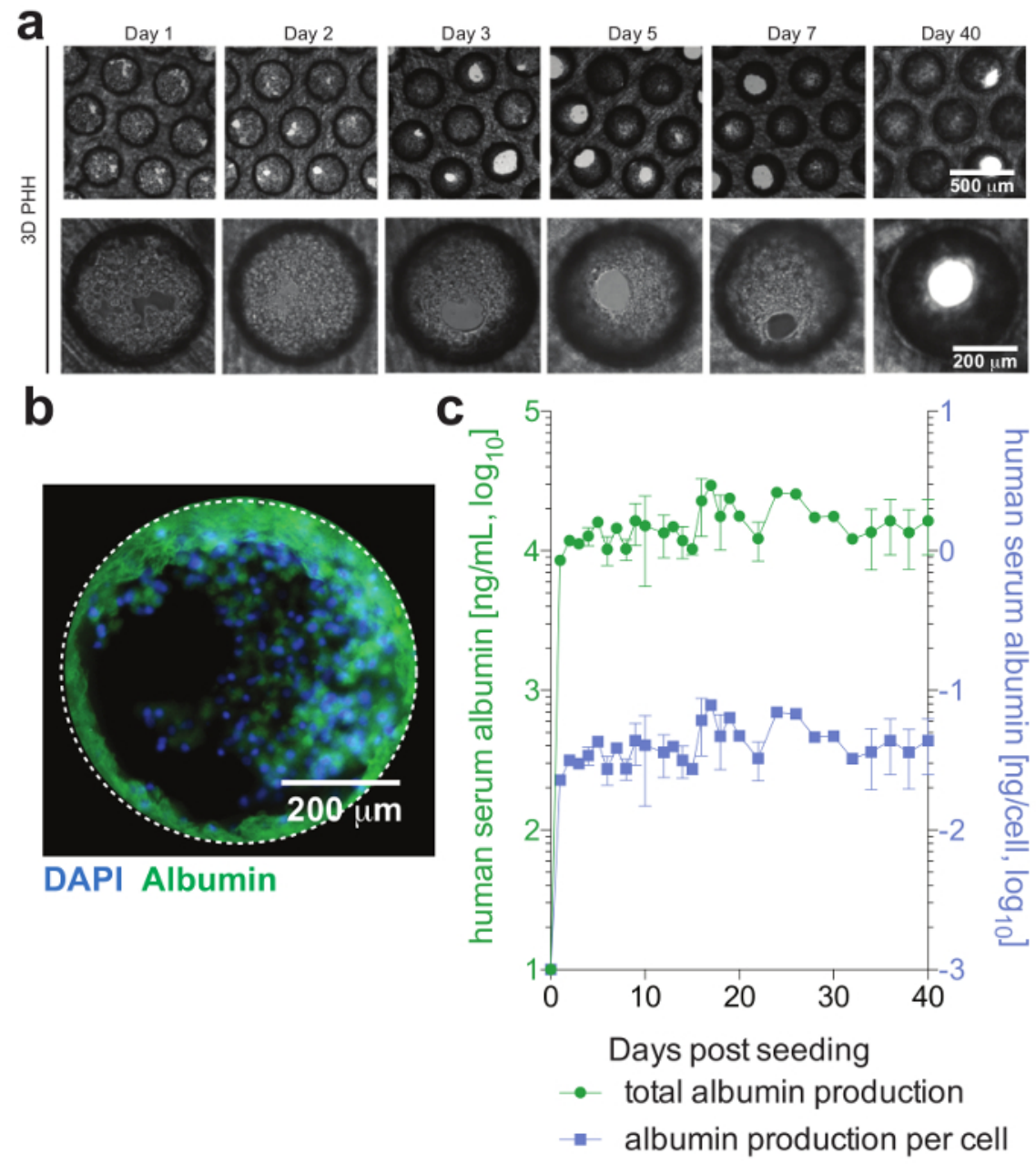

Figure 2: Hepatic microtissue formation and hepatocyte viability. (a) This panel shows longitudinal brightfield images of 3D hepatocyte monocultures demonstrating microtissue formation following seeding. (b) This panel shows immunofluorescence imaging of cultures for nuclei (blue) and human albumin (green). (c) This panel shows longitudinal total albumin, as well as per cell adjusted albumin production, during 40 days of hepatocyte monocultures, as determined by ELISA. The data shown are mean \pm SD. This figure is adapted from Ortega-Prieto et al. ${ }^{4}$. Please click here to view a larger version of this figure. 


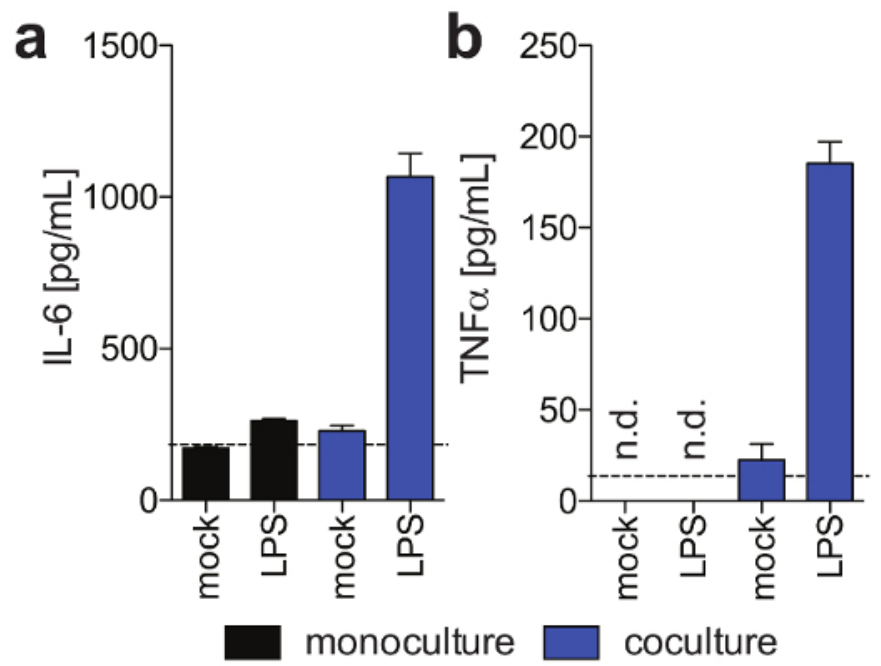

Figure 3: Kupffer cell functionality in 3-D cocultures. These panels show the secretion of (a) IL6 and (b) TNFa in hepatocyte monocultures and hepatocyte/Kupffer cell cocultures 11 days post-seeding in response to exogenously added LPS at day 9 post seeding, as determined using Human Magnetic Luminex assay. This figure is adapted from Ortega-Prieto et al. ${ }^{4}$. Please click here to view a larger version of this figure.

a

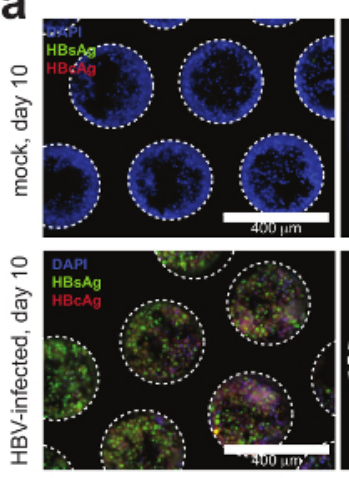

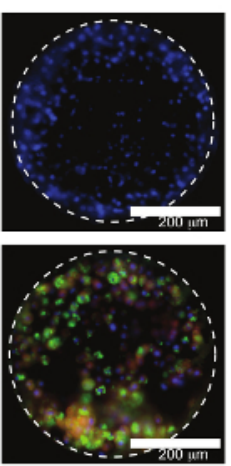

b

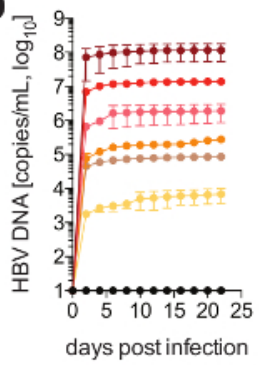

C

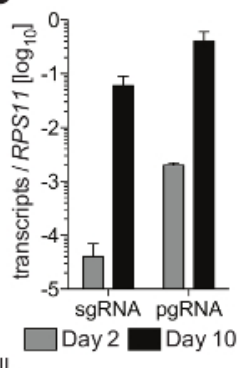

$\rightarrow$ mock $\rightarrow 5 \mathrm{GE} /$ cell

$\because 5000 \mathrm{GE} / \mathrm{cell} \rightarrow 0.5 \mathrm{GE} / \mathrm{cell}$

$\because 500 \mathrm{GE} /$ cell $\rightarrow 0.05 \mathrm{GE} / \mathrm{cell}$

Figure 4: HBV infection in liver-on-a-chip cultures. (a) This panel shows the immunofluorescence microscopy detection of $\mathrm{HBcAg}$ (red), HBsAg (green), and nuclei (blue) 10 days following the infection of the cultures with HBV. (b) This panel shows the susceptibility of the cultures to HBV infection using different multiplicities of infection, as determined by a quantification of HBV DNA in the culture supernatants. (c) This panel shows the quantification of the longitudinal accumulation of HBV pgRNA relative to the housekeeping gene RPS11. The data shown are mean \pm SD. This figure is adapted from Ortega-Prieto et al. ${ }^{4}$. Please click here to view a larger version of this figure.

\section{Discussion}

The challenges in maintaining long-term cultures of $\mathrm{PHH}$ have driven the development of several culture models with increased functionality and longevity, each exhibiting differential advantages and disadvantages. It is now widely acknowledged that static $2 \mathrm{D}$ cultures of $\mathrm{PHH}$ are mimicking certain aspects of hepatocyte biology for very limited amounts of time. Thus, micropatterned cocultures ${ }^{12,13}$, spheroid cultures ${ }^{14,15}$, and $3 \mathrm{D}$ liveron-a-chip cultures ${ }^{16,17}$ are rapidly replacing these more basic systems. Especially when studying infectious diseases, which have coevolved with their host to utilize specific microenvironments, the requirement for providing physiological environments is underpinned by the often challenging nature of culturing human-tropic infectious diseases, including hepatitis C virus, HBV, and malaria.

The most critical step in performing 3D liver-on-a-chip cultures is the quality of the initially sourced primary cell types. These cells should be tested for their adherence capacity and only plateable PHH lots should be used in order to ensure successful tissue formation and culture generation. Even though freshly isolated PHH can be used, their cryopreservation is usually complicated and requires special rate-controlled freezers.

In contrast to conventional static 2D cultures, the host genetic background is negligible in regard to susceptibility to HBV infection, and all thusfar tested hepatocyte donors are able to establish HBV infection ${ }^{4}$.

Even though patient-derived HBV establishes infections of 3D cultures, it is imperative to utilize PEG-precipitated and sucrose cushion-purified HBV whenever using inducible HBV producer cell lines for the generation of viral inocula. Cell culture supernatants directly applied to 3D liveron-a-chip cultures, either through the presence of inhibitory factors or due to an incompatibility of present growth factors with hepatocytes, do not readily result in infection. Additionally, when selecting patient-derived viral inocula, only serum should be used, since plasma inevitably coagulates and clogs the microfluidic circulation of the culture platform. 
Irrespective of the viral inoculum used, assuring cellular viability and differentiation, as well as ensuring complete removal of the initial HBV inoculum, is key to successful long-term infection studies. The most convenient way to do this is sampling cultures following the removal of the viral inoculum, as well as measuring human serum albumin levels throughout the culture period. Of note, similarly to all other described platforms, HBV infection, once established, does not readily spread to uninfected cells. The underlying mechanism for this remains elusive since HBV infection in vivo readily infects the majority of the hepatocytes within the liver.

In regard to cocultures of $\mathrm{PHH}$ and Kupffer cells, it is advisable to perform lot tests of Kupffer cells to evaluate IL6 and TNFa secretion in response to LPS stimulation, since not all commercially available Kupffer cell donors have an equal responsiveness.

Importantly, for all drug treatments or initial infection of cultures with HBV, the total volume of the well $(1.4 \mathrm{~mL})$, as well as of the microfluidic channel $(0.2 \mathrm{~mL})$, must be taken into account for the calculation of drug or inoculum concentrations. In order to assure accurate dosing, one washing step with medium containing HBV or drugs is performed in order to prime the microfluidic channel.

The platform used utilizes $600,000 \mathrm{PHH}$ per well, which ensures multilayered hepatocytes within the scaffolds. Even though the cell number can be varied, the chosen cell concentration ensures optimal results. The plate format holds a total of 12 scaffolds, which can be upgraded to 36 scaffolds. However, due to microfluidic requirements, scaling up to higher well numbers is not possible to date.

Using these approaches, cultures can be maintained with optimal cell performance for at least 40 days, which, thus far, offers unprecedented opportunities to evaluate novel drug candidates, as well as study the complex interplay between different hepatic cell populations during HBV infection.

\section{Disclosures}

The authors have nothing to disclose.

\section{Acknowledgments}

This work was funded by a Starter grant from the European Research Council (637304), a Wellcome Trust Investigator Award (104771/Z/14/Z), and by CN Bio Innovations.

\section{References}

1. Verrier, E. R., Colpitts, C. C., Schuster, C., Zeisel, M. B., Baumert, T. F. Cell Culture Models for the Investigation of Hepatitis B and D Virus Infection. Viruses. 8 (9) (2016).

2. Elaut, G. et al. Molecular mechanisms underlying the dedifferentiation process of isolated hepatocytes and their cultures. Current Drug Metabolism. 7 (6), 629-660 (2006).

3. Konig, A. et al. Kinetics of the bile acid transporter and hepatitis B virus receptor $\mathrm{Na}+$ /taurocholate cotransporting polypeptide (NTCP) in hepatocytes. Journal of Hepatology. 61 (4), 867-875 (2014).

4. Ortega-Prieto, A. M. et al. 3D microfluidic liver cultures as a physiological preclinical tool for hepatitis B virus infection. Nature Communications. 9 (1), 682 (2018).

5. Allweiss, L., Dandri, M. The Role of cccDNA in HBV Maintenance. Viruses. 9 (6) (2017).

6. Guo, J. T., Guo, H. Metabolism and function of hepatitis B virus cccDNA: Implications for the development of cccDNA-targeting antiviral therapeutics. Antiviral Research. 122, 91-100 (2015).

7. Lucifora, J. et al. Direct antiviral properties of TLR ligands against HBV replication in immune-competent hepatocytes. Scientific Reports. 8 (1), 5390 (2018).

8. Hosel, M. et al. Hepatitis B Virus Activates Signal Transducer and Activator of Transcription 3 Supporting Hepatocyte Survival and Virus Replication. Cellular and Molecular Gastroenterology and Hepatology. 4 (3), 339-363 (2017).

9. Mazza, G. et al. Rapid production of human liver scaffolds for functional tissue engineering by high shear stress oscillation-decellularization Scientific Reports. 7 (1), 5534 (2017).

10. Hang, T. C., Lauffenburger, D. A., Griffith, L. G., Stolz, D. B. Lipids promote survival, proliferation, and maintenance of differentiation of rat liver sinusoidal endothelial cells in vitro. American Journal of Physiology-Gastrointestinal and Liver Physiology. 302 (3), G375-388 (2012).

11. Hwa, A. J. et al. Rat liver sinusoidal endothelial cells survive without exogenous VEGF in 3D perfused co-cultures with hepatocytes. The FASEB Journal. 21 (10), 2564-2579 (2007).

12. Khetani, S. R., Bhatia, S. N. Microscale culture of human liver cells for drug development. Nature Biotechnology. 26 (1), $120-126$ (2008).

13. March, S. et al. Micropatterned coculture of primary human hepatocytes and supportive cells for the study of hepatotropic pathogens. Nature Protocols. 10 (12), 2027-2053 (2015).

14. Bell, C. C. et al. Characterization of primary human hepatocyte spheroids as a model system for drug-induced liver injury, liver function and disease. Scientific Reports. 6, 25187 (2016).

15. Tong, W. H. et al. Constrained spheroids for prolonged hepatocyte culture. Biomaterials. 80, 106-120 (2016).

16. Griffith, L. G., Wells, A., Stolz, D. B. Engineering liver. Hepatology. 60 (4), 1426-1434 (2014).

17. Domansky, K. et al. Perfused multiwell plate for 3D liver tissue engineering. Lab Chip. 10 (1), 51-58 (2010). 